\title{
An endothelial rejection line following Descemet stripping automated endothelial keratoplasty
}

\author{
Muhannad Alkhalifah', Bader Alqahtani², Abdulmohsen Almulhim ${ }^{3}$ and Waleed Alsarhani ${ }^{1 *}$
}

\begin{abstract}
Background: The endothelial rejection line is rarely seen after Descemet stripping automated endothelial keratoplasties (DSAEKs). Here, we present a case of endothelial graft rejection with an endothelial rejection line occurring 1 year after the procedure.

Case presentation: A 58-year-old female presented with graft rejection 1 year following a DSAEK procedure. The episode started when she tapered down her loteprednol to once a day. Slit-lamp examination showed a mildly injected conjunctiva with 1+ corneal oedema. On the posterior surface of the cornea, there was an endothelial rejection line (Khodadoust line) with keratic precipitates and multiple areas of anterior synechia.
\end{abstract}

Conclusion: The classic endothelial rejection line should be kept in mind as a rare sign of DSAEK graft rejection.

Keywords: Corneal transplant, Graft rejection, DSAEK, Endothelial rejection line

\section{Background}

The rate of graft rejection following endothelial keratoplasties is significantly lower than that following penetrating keratoplasties (PKPs) [1]. Hence, endothelial keratoplasties have largely replaced PKP in treating endothelial diseases such as Fuchs endothelial dystrophy and pseudophakic bullous keratopathy. Moreover, graft rejection after endothelial keratoplasty is entirely endothelial. Early recognition and treatment of endothelial graft rejection is of extreme importance. Signs of endothelial graft rejection include keratic precipitates (KPs), corneal oedema and an anterior chamber reaction. According to different studies on Descemet stripping automated endothelial keratoplasty (DSAEK) complications, the 3 -year incidence of immunologic graft rejection episodes ranges from 4 to $22 \%$ [1-5]. A recent study by

\footnotetext{
* Correspondence: WAlsarhani@gmail.com

${ }^{1}$ Department of Ophthalmology, College of Medicine, King Saud University, Riyadh, Saudi Arabia

Full list of author information is available at the end of the article
}

Price et al. found that endothelial rejection occurs in $7.9 \%$ of DSAEK cases over a 5-year period [6]. A number of studies have reported no endothelial rejection lines [2-4], although two studies have reported these lines [1,7]. Here, we present a case of endothelial graft rejection with an endothelial rejection line occurring 1 year after DSAEK.

\section{Case presentation}

A 58-year-old female presented with a one-week history of blurred vision associated with photophobia and redness. The episode started when she tapered her loteprednol from twice a day to once a day. The patient underwent DSAEK regrafting 1 year before her presentation. Her first DSAEK procedure had been performed 4 years prior for a decompensated cornea secondary to an iris-fixated anterior chamber lens. Her best corrected visual acuity in the right eye was $20 / 200$, and the intraocular pressure was $9 \mathrm{mmHg}$. Slit-lamp examination showed a mildly injected conjunctiva with $1+$ corneal oedema (Fig. 1). On the 


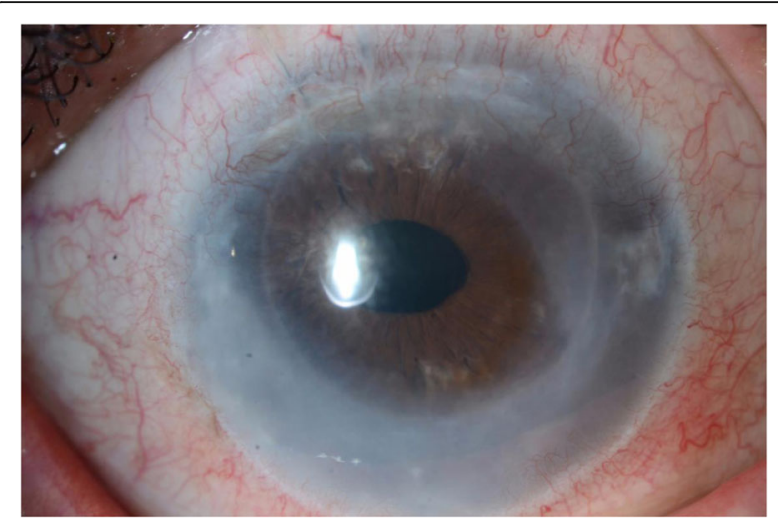

Fig. 1 Diffuse corneal oedema in a grafted eye

posterior surface of the cornea, there was an endothelial rejection line (Khodadoust line) with KPs extending from 4 to 8 o'clock (Fig. 2). Additionally, there were multiple areas of anterior synechia. The pupil was irregular and oval in shape, and the anterior chamber was deep with occasional cells. Examination of the left eye was unremarkable. The patient had a central corneal thickness of $659 \mu \mathrm{m}$ (measured by anterior segment optical coherence tomography) on initial presentation (Fig. 3). The diagnosis of graft rejection was made, and the patient was started on prednisolone acetate $1 \%$ drops every $1 \mathrm{~h}$. After 1 month of follow-up, the patient's vision improved from $20 / 200$ to $20 / 60$, and the corneal oedema also improved (Fig. 4).

\section{Discussion and conclusion}

The rate of graft rejection after DSAEK is significantly lower than that after PKP $[4,8]$. This is explained by the lower number of sutures, the absence of graft exposure to ocular-surface antigenpresenting cells, the lack of contact with stromal blood vessels, and the fact that DSAEK involves less

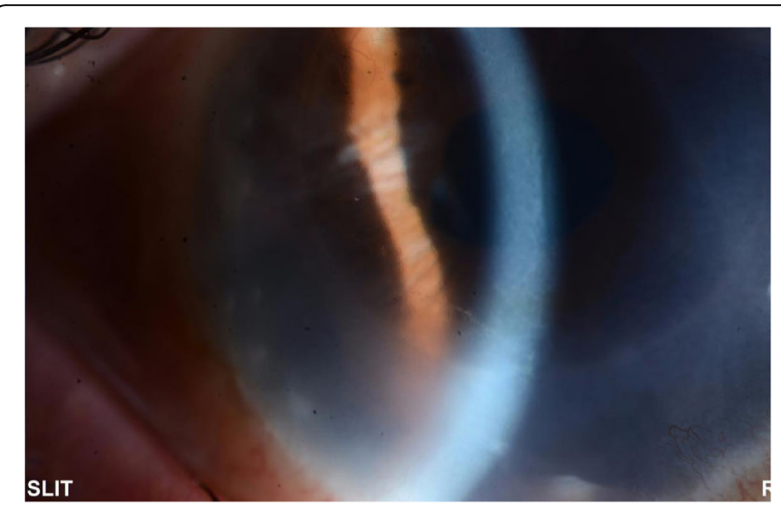

Fig. 2 Endothelial rejection line (Khodadoust line) immunogenic donor tissue than PKP $[8,9]$. In a study performed by Basak et al., two-thirds of patients who experienced graft rejection in a period between 1 and 3 years after surgery complained of blurred vision and photophobia, while the other onethird presented graft rejection that was discovered incidentally during a routine follow-up clinical evaluation. All of the patients who had DSAEK rejection exhibited KPs, anterior chamber cells, and diffuse corneal oedema. However, none of these cases developed an endothelial rejection line [2].

The endothelial rejection line (Khodadoust line) is an aggregation of lymphoid cells on the corneal endothelial side and is a sign of immunologic corneal allogenic graft rejection [10], which has been classically described after PKP. In a study by Jordan et al., no cases of an endothelial rejection line were reported among their 54 patients who experienced immunological graft rejection episodes after DSAEK [3]. The researchers noted that stromal vascularization is often associated with the site of an endothelial rejection line in PKP, so the comparative absence of stromal vessels extending into DSAEK tissue may reduce the likelihood of an endothelial rejection line. In our patient, iridocorneal adhesions possibly triggered immune rejection of the graft. Three to four quadrants of anterior synechia have been reported to be a strong risk factor for graft rejection [11]. In murine models, anterior synechia triggered a cytotoxic $\mathrm{T}$ lymphocyte response with more cytokine expression and eventually a higher rejection rate compared to models without anterior synechia [12]. Saelens et al. and Fiorentzis et al. reported two cases of endothelial rejection line following DSAEK with no stromal vascularization, similar to our case, but with no anterior synechia [7, 13]. Therefore, we believe stromal vascularization and anterior synechia are factors that may increase the likelihood of the formation of the rejection line, but they do not have to be present.

In our patient, graft rejection with the endothelial rejection line was encountered 1 year post-DSAEK shortly after she tapered the corticosteroid drops from twice daily to once daily. Our patient was treated with an aggressive topical steroid regimen, and her visual acuity improved over a short period of time. This shows the importance of early recognition and prompt treatment for a favourable clinical outcome. It is of vital importance to instruct the patient undergoing DSAEK regarding the careful use of postoperative medications and the consequences of poor compliance. In our patient, the rejection episode could be attributed to tapering the topical steroids. In the case of an endothelial rejection line 


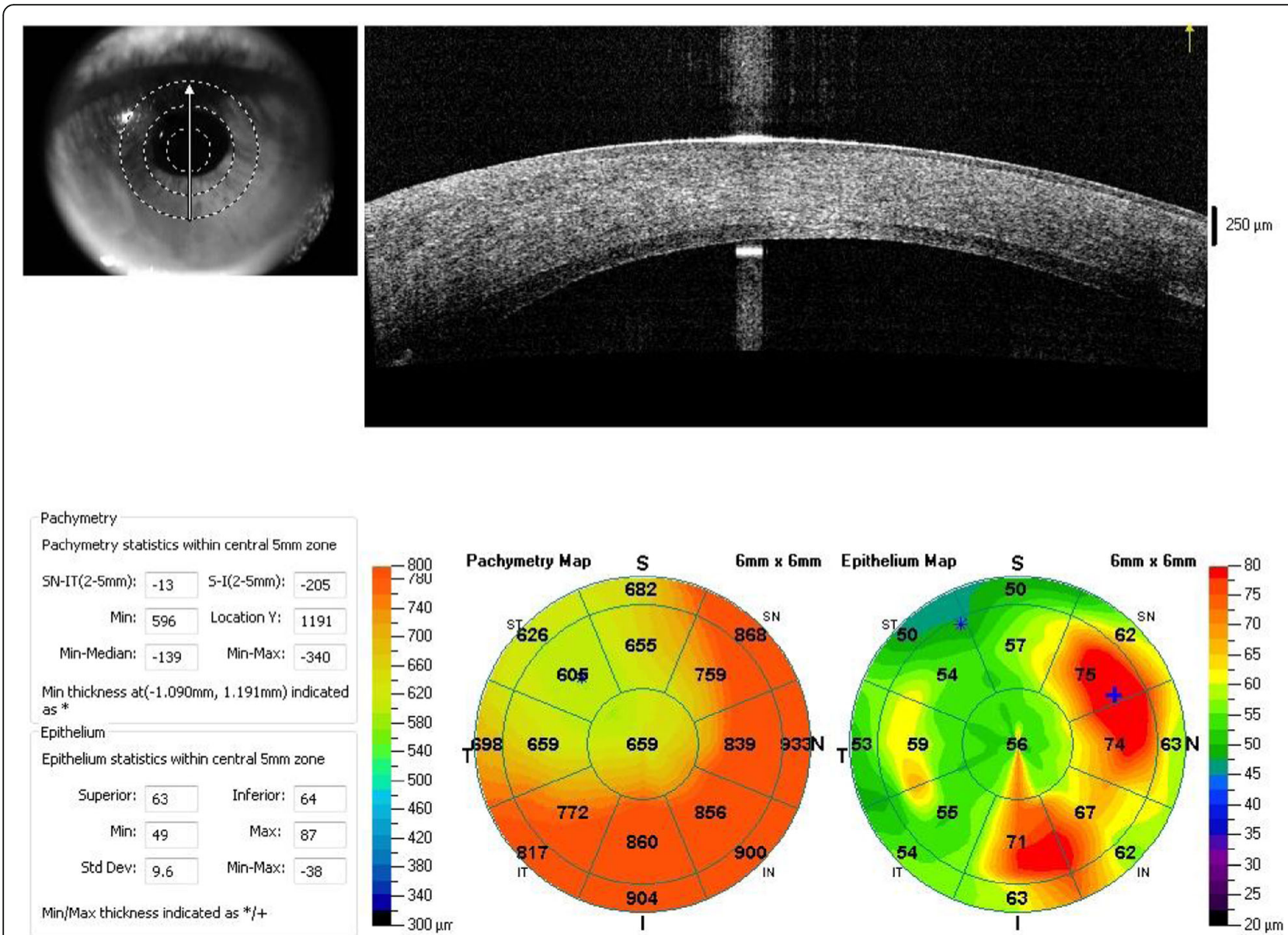

Fig. 3 Anterior segment optical coherence tomography showing an attached lenticule with a central corneal thickness of $659 \mu m$

following DSAEK that was reported by Saelens et al., the patient had stopped the steroid drops 1 month after her operation [7]. The cessation of steroids postoperatively was found to be the most predictive factor for the development of DSAEK rejection, with a 5.5-fold greater risk, as shown by Wu et al. [1]. A

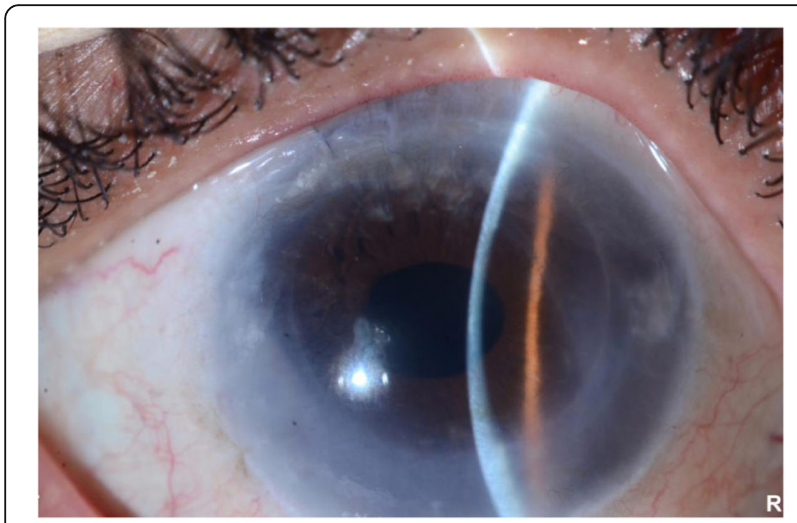

Fig. 4 Improvement in corneal oedema 4 weeks after diagnosis and treatment similar observation was reported by Sepsakos et al. [4], as termination of steroid use was found to be the strongest risk factor for graft rejection. However, a more recent study did not find topical corticosteroid termination to be a significant factor predisposing to endothelial rejection after DSAEK [5]. In addition, close follow-up, especially in the first postoperative year, and subsequent long-term follow-up have been found by $\mathrm{Wu}$ et al. to be the most important factor in varying immunologic graft rejection rates [1].

As we described, the present case shows that the endothelial rejection line is a rare but important sign of endothelial rejection following DSAEK. Furthermore, the present case raises the possibility that anterior synechia may trigger the formation of Khodadoust lines. Since this is a single case report, it is difficult to explain the underlying mechanism and risk factors associated with the endothelial rejection line following endothelial keratoplasties. Indeed, the classic endothelial rejection line should be kept in mind as a rare sign of DSAEK graft rejection. 


\section{Abbreviations}

PKP: Penetrating keratoplasty; DSAEK: Descemet stripping automated endothelial keratoplasty; KP: Keratic precipitate

\section{Acknowledgements}

None.

\section{Authors' contributions}

All authors have read and approved the manuscript. MA provided clinica information and figures. BA participated in writing the manuscript. AA provided clinical information about the case. WA wrote and revised the manuscript.

\section{Funding}

This research did not receive any specific grant from funding agencies in the public, commercial, or not-for-profit sectors.

\section{Availability of data and materials}

Data sharing was not applicable to this article, as no datasets were generated or analysed during the current study.

\section{Ethics approval and consent to participate}

Not applicable.

\section{Consent for publication}

Written informed consent was obtained from the patient for publication of this report and any accompanying images and videos. A copy of the written consent is available for review by the Editor of this journal.

\section{Competing interests}

The authors declare that there are no conflicts of interest.

\section{Author details}

'Department of Ophthalmology, College of Medicine, King Saud University, Riyadh, Saudi Arabia. ${ }^{2}$ Department of Ophthalmology, King Abdulaziz Medical City, Jeddah, Saudi Arabia. ${ }^{3}$ Department of Ophthalmology, College of Medicine, Jouf University, Sakakah, Al-Jouf, Saudi Arabia.

Received: 2 April 2020 Accepted: 20 July 2020

Published online: 29 July 2020

\section{References}

1. Wu El, Ritterband DC, Yu G, Shields RA, Seedor JA. Graft Rejection Following Descemet Stripping Automated Endothelial Keratoplasty: Features, Risk Factors, and Outcomes. Am J Ophthalmol. 2012;153(5):949-57 e1.

2. Basak SK, Basak S. Complications and management in Descemet's stripping endothelial keratoplasty: analysis of consecutive 430 cases. Indian J Ophthalmol. 2014;62(2):209-18.

3. Jordan CS, Price MO, Trespalacios R, Price FW Jr. Graft rejection episodes after Descemet stripping with endothelial keratoplasty: part one: clinical signs and symptoms. Br J Ophthalmol. 2009;93:387-90.

4. Sepsakos L, Shah K, Lindquist T, Lee W, Holland E. Rate of rejection after descemet stripping automated endothelial keratoplasty in Fuchs dystrophy: three-year follow-up. Cornea. 2016:35(12):1537-41.

5. Stulting RD, Lass JH, Terry MA, Benetz BA, Cohen NJ, Ayala AR, et al. Factors associated with graft rejection in the cornea preservation time study. Am J Ophthalmol. 2018;196:197-207.

6. Price DA, Kelley M, Price FW Jr, Price MO. Five-year graft survival of Descemet membrane endothelial Keratoplasty (EK) versus Descemet stripping EK and the effect of donor sex matching. Ophthalmology. 2018; 125(10):1508-14

7. Saelens IE, Bleyen I, Bartels MC, Van Rij G. A posterior khodadoust line in a graft rejection episode after descemet stripping automated endothelial keratoplasty. Cornea. 2011;30(2):245-6.

8. Hos D, Matthaei M, Bock F, Maruyama K, Notara M, Clahsen T, et al. Immune reactions after modern lamellar (DALK, DSAEK, DMEK) versus conventional penetrating corneal transplantation. Prog Retin Eye Res. 2019:73:100768.

9. Prakash $\mathrm{G}$, Jhanji V, Titiyal J. Will Descemet's stripping with automated endothelial keratoplasty (DSAEK) lower the rates of allograft rejection in corneal transplants for endothelial failure? Med Hypotheses. 2007;69:1117-9.
10. Saboori M, Fatteh N. Khodadoust Line. In: Schmidt-Erfurth U, Kohnen T, editors. Encyclopedia of Ophthalmology. Berlin: Springer Berlin Heidelberg; 2018. p. 1011-2

11. Maguire MG, Stark WJ, Gottsch JD, Stulting RD, Sugar A, Fink NE, et al. Risk factors for corneal graft failure and rejection in the collaborative corneal transplantation studies. Collaborative corneal transplantation studies research group. Ophthalmology. 1994;101(9):1536-47.

12. Yamagami S, Tsuru T. Increase in orthotopic murine corneal transplantation rejection rate with anterior synechiae. Invest Ophthalmol Vis Sci. 1999; 40(10):2422-6

13. Fiorentzis M, Viestenz A, Seitz B. Immunological graft rejection with Khodadoust line after "Descemet stripping automated endothelial keratoplasty" (DSAEK). Ophthalmologe. 2015;112(9):783-7.

\section{Publisher's Note}

Springer Nature remains neutral with regard to jurisdictional claims in published maps and institutional affiliations.
Ready to submit your research? Choose BMC and benefit from:

- fast, convenient online submission

- thorough peer review by experienced researchers in your field

- rapid publication on acceptance

- support for research data, including large and complex data types

- gold Open Access which fosters wider collaboration and increased citations

- maximum visibility for your research: over $100 \mathrm{M}$ website views per year

At BMC, research is always in progress.

Learn more biomedcentral.com/submissions 